\title{
The Ant Trap
}

Rebuilding the Foundations of the Social Sciences

BRIAN EPSTEIN 


\section{CONTENTS}

Introduction 1

PART ONE FOUNDATIONS, OLD AND NEW 11

1. Individualism: A Recipe for Warding off "Spirits" 13

2. Getting to the Consensus View 23

3. Seeds of Doubt 36

4. Another Puzzle: A Competing Consensus 50

5. Tools and Terminology 61

6. Grounding and Anchoring 74

7. Case Study: Laws as Frame Principles 88

8. Two Kinds of Individualism 101

9. Against Conjunctivism 115

\section{PART TWO GROUPS AND THE FAILURE OF INDIVIDUALISM 129}

10. Groups and Constitution 133

11. Simple Facts about Groups 150

12. The Identity of Groups 169

13. Kinds of Groups $\quad 182$ 
14. Group Attitudes: Patterns of Grounding 197

15. Group Action: More than Member Action 217

16. Group Intention 236

17. Other Theories I: Social Integrate Models 250

18. Other Theories II: Status Models 264

Looking Ahead 276

Acknowledgments 281

Bibliography 283

Index 293 


\section{Introduction}

Shortly after I got out of college, back in the early 1990s, I took a job at a management consulting firm. The firm was employed by mammoth companies like Gillette and AT\&T, doing projects that now seem almost absurd. A team consisting of several "analysts" like me and a couple of "managers" just out of business school would spend weeks writing questionnaires-How often do you make international calls? Is a close shave most important to you, or is it more important to avoid razor burn? Then we would send researchers into malls across the country, stacks of questionnaires in hand. They would survey five to eight hundred people, and our statistics department would type the responses into a computer, analyze them, and send us the results. We would then take those results, sketch out a set of bar charts and scattergraphs, and finally hand them to the production department (in those pre-PowerPoint days) to make a slick presentation.

Companies paid hundreds of thousands of dollars for those presentations. (Sadly, I was a lowly analyst, so I only saw these numbers on the invoices, not in my bank account.) There was a reason they paid so much. They needed information about people-what they buy, what they read, what they do in their spare time, whom they vote for, and how they shave-and there was no other way to get it. These companies had policy decisions to make: what products to develop and what to abandon, which markets to enter and which to flee, whether to hike prices or reduce the length of warranties. In 1993, doing expensive little surveys was the best way to inform such decisions.

The last twenty years have seen a revolution in how we collect data about people. Today, a company does not need to pay the price of a house in Boston to survey 800 mall-walkers. People are throwing information at companies as fast as those companies can collect it. In the next month, 200 million people will run 13 billion searches on Google in the United States alone. In the same period, Facebook will compile personal information from 1.3 billion people across the world. Walmart will process and record 7 billion purchases by 100 million people. Verizon, AT\&T, and other wireless carriers will record the 
locations of 110 billion telephone calls made by 280 million people, and will track the senders and recipients of 170 billion text messages. Nowadays, running a manual survey of 800 people would be both inefficient and unscientific.

Much of this transformation is, of course, explained by technologies: the internet and mobile phones; point-of-sale, tracking, and surveillance systems; data analysis and pattern recognition software; computer processing and storage; and so on. But technology is only part of the explanation. Nearly as important is social change. People have turned out to be surprisingly eager to publicize their personal information. Contemporary labor markets are pushing each of us to advertise ourselves. And the ecosystem of modern corporations has made it an imperative of survival to use personal information in order to increase profits.

Increasingly, economic activity turns on collecting and mobilizing information about people. Industries built for this purpose now dwarf the traditional academic departments and think-tanks that once dominated the social sciences. Google-whose business, after all, is directing people to documents written by people and tailoring advertisements to people-has over 35,000 employees, more than twice the 13,000 academic economists in the United States. And the marketing department of Procter and Gamble is larger than the sociology departments of all US universities combined. It is only a slight exaggeration to say that the world economy is transforming into a massive system for doing social science. For all our talk of the "information economy," the "knowledge economy," and the "technology economy," a more accurate name for the present epoch is the "social sciences economy."

\section{The Paradox of the Social Sciences}

Given all this, you would think the social sciences themselves, wielding data that just a few years ago no one had dreamed possible, would be riding high. But despite it all —all the data and all the computers and all the corporate attention - the social sciences are hardly budging. So far, the new advantages have been of little help in deciding among conflicting theories of the workings of the economy, the sources of poverty, the prescriptions for improving education, and financial regulation. If anything, the last few years have deflated whatever optimism we might have had about social theory.

The latest blow came in the form of the recent financial crisis. Just a few years before, economists were gaining confidence in their abilities to understand and guide social systems. In 2004, Ben Bernanke, before becoming chairman of the Federal Reserve, wrote a paper describing the "Great 
Moderation" in the global economic system. ${ }^{1}$ Like many other economists, Bernanke was impressed by the apparent decline of risk in financial markets, as economies grew less volatile. He saw an end to the successive crises of earlier generations. Bernanke weighed three possible explanations. Perhaps this Great Moderation was a result of structural changes in the economy, such as the shift from manufacturing to services. Perhaps it was a result of improved macroeconomic policies, guided by contemporary economics. Or perhaps it was just good luck.

Of these three possibilities, the second one represents a triumph of applied social science. And this is the explanation Bernanke found evidence to support. "I think it is likely," said Bernanke, "that the policy explanation for the Great Moderation deserves more credit than it has received in the literature." In a classic case of poor timing, Olivier Blanchard, chief economist at the International Monetary Fund, published a paper in early 2008 agreeing with this assessment, saying "The state of macroeconomics is good."3

These pronouncements were premature. The unraveling of financial markets in late 2008 took the profession by surprise, its speed and magnitude terrifying economists and policymakers alike. Amid the crisis, the economics profession did not have even roughly consistent recommendations about how to react to it. Prominent economists excoriated the Treasury and the Federal Reserve for every action they took and for every action they failed to take: for allowing Lehman Brothers to fail, for bailing out AIG and protecting its creditors from losses, for pushing an economic stimulus, for effectively nationalizing Fannie Mae and Freddie Mac, for three episodes of quantitative easing, and so on. Inasmuch as the financial authorities deserve some credit-which they surely do-probably the best that can be said is that they did a good job putting out short-term fires, and avoided wholesale catastrophe. But there was no unified theory guiding them.

Since the crisis, economists have been wringing their hands about the discipline. Paul Krugman has been a vocal critic, titling his cover article for the New York Times Magazine "How Did Economists Get It So Wrong?"4 But even the most orthodox voices were shaken. Alan Greenspan, testifying to Congress in 2009, disowned some of his most deeply held beliefs about the rationality of markets: "The whole intellectual edifice," he admitted, "collapsed in the summer of last year." The economist Andrew Lo has reviewed 21 books on

${ }^{1}$ Bernanke (2004) 2012.

${ }^{2}$ Bernanke (2004) 2012, 159.

${ }^{3}$ Blanchard 2008. See also Cassidy 2010, Krugman 2009, Kirman 2010.

${ }^{4}$ Krugman 2009.

${ }^{5}$ Alan Greenspan, testifying before the House Committee on Oversight and Government Reform on October 23, 2008. 
the financial crisis, and concluded, "there is still significant disagreement as to what the underlying causes of the crisis were, and even less agreement on what to do about it."6 And Olivier Blanchard has withdrawn his optimism, retracting his earlier views in a paper titled "Rethinking Macroeconomic Policy."

This swing, from unrelenting optimism to self-critical breast-beating, is a familiar story in the social sciences. One doesn't have to be a historian to think of innumerable times that social scientists played the role of Icarus (or Wile E Coyote), thinking they have safely taken flight, only to plunge to earth. Over and over, we have seen plausible theories across the social sciences slapped down.

As compared to past crises, the overconfidence of theorists in 2008 was not extreme. In fact, this is what is depressing about our latest episode. Part of what is noteworthy about the situation today is that, preceding the crisis, the ambitions of social scientists were actually fairly limited. We thought we had learned, through theory and trial and error, not how to create a utopia on earth, not how to solve the world's social ills, but just how to avoid wild economic swings and massive recessions.

\section{Reactions}

Many people inside and outside the profession have reacted to the failures of social science as Friedrich Hayek did, back in the 1940s: namely, economies and societies are unimaginably complex systems. As a result, policymakers cannot possibly have enough knowledge to make choices on behalf of a society as a whole. Chances are that they will be worse at it than a distributed market will. Therefore, it is folly even to try to explain, predict, or direct economic activity. In the face of policymaker ignorance, we should minimize policy and regulation, letting the market direct itself rather than trying to give it any direction from above.

A different response to the failures of social science is to be a conservative in the style of Edmund Burke, the eighteenth-century political theorist. Burke too argued that economies and society are too complex to understand. But instead of concluding that we should minimize regulation, he argued that we should be suspicious of abstract reasoning and radical change of any kind. Whatever we do, there is a good chance we will make things worse than they are. On a Burkean approach, it is not the absolute level of regulation that should be minimized, but the pace of change.

${ }^{6}$ Lo 2012.

${ }^{7}$ Blanchard et al. 2010, Blanchard 2011. 
There is value in both of these reactions. But if the last few years have shown anything, it is that refusing to design and intervene in social systems is often worse than designing them in partial ignorance. Many recent policy failures have been a result of under-design, from Donald Rumsfeld's failed "hands off" policy in the Iraq reconstruction to the limits on financial regulation in recent years. Likewise, Burkean conservatism is untenable in many domains. As the economist Paul Romer recently pointed out, if you adopt a set of financial regulations and keep them unchanged, the markets will find a way around them, and ten years later, you'll have a financial crisis. ${ }^{8}$ Though they continually disappoint us, theory-led policy interventions - that is, the prescriptions of the social sciences-are indispensable.

What, then, has gone wrong with theories in the social sciences? Why, despite the information revolution, are we not better off? There is no shortage of diagnoses out there. With each failure of the social sciences, theorists have turned their critical sights toward its methods. In many ways, the various methods of the social sciences have been found wanting. The prevailing diagnoses fall, more or less, into five general categories:

(1) Our models of the individual are inadequate. Individuals are modeled as rational, when they are not rational. They are modeled as being similar to one another, when they are radically heterogeneous. They are modeled as having perfect information about the world and about the future, and as being perfect calculators of their own interests, when they are far from it. They are modeled as being independently operating atoms, when they are socially constituted. All of these diagnoses criticize the way widely used models treat individual people. ${ }^{9}$

(2) We have a poor understanding of the "emergence" of group properties out of aggregates of individuals. Systems of interacting parts often have very different properties than the individuals that compose them. A brain has different properties than individual neurons, an ant colony has different properties than the individual ants, and likewise a society has properties that cannot easily be predicted from the properties of individuals. The diagnosis is that our models of individuals may be ok, but our theories are not good at determining how individuals aggregate into large groups. ${ }^{10}$

(3) We are building models in the wrong style. Some theorists hold that our models are too mathematical, or that we have been seduced by the elegance of

\footnotetext{
${ }^{8}$ Romer 2011.

${ }^{9}$ For discussion of a number of these in economics, see Colander 1996.

${ }^{10}$ Approaches to aggregation are omnipresent in the social sciences, drawing on fields such as equilibrium theories, network theory, theories of complex systems, and many others.
} 
certain abstract structures that do not reflect the real world. Others argue that models in the social sciences are not mathematical enough, or use mathematics incorrectly. Still others argue that we will never be able to model society in terms of systems of equations, but that we should perform computer simulations instead. ${ }^{11}$

(4) We are building models at the wrong level. From the beginning, the social sciences have been bitterly divided about the right "level" for social explanations. Some theorists argue that macroscopic social phenomena, such as financial bubbles or the growth of economies, can only be explained in terms of other macroscopic social phenomena. Others are committed to explaining social phenomena in terms of individuals. Recently, some theorists have even argued that individuals are too "high-level," and that social theory should be founded in neuroscience. ${ }^{12}$

(5) "Grand theorizing" is out of our reach altogether. In recent years, many social scientists have grown suspicious of theories that intend to model societies or economies as a whole. In fact, one of the hottest fields in economics today involves only minimal theory. Instead, it takes its cues from medicine, designing and running randomized trials. Other theorists are devoting their energies to small models that test hypotheses about very narrow parts of the economy. ${ }^{13}$

Different research strategies correspond to each of the prevailing diagnoses. If the rational choice model of the individual is a problem, we should develop more refined theories of individual choice. If the problem is the aggregation of individuals, we should develop mathematical or computational techniques. If the problem is grand theorizing, we should develop experimental methods such as randomized testing.

\section{A Deeper Flaw: The Anthropocentric Picture of the Social World}

All of these are plausible diagnoses. To some extent, each of these avenues needs to be explored if we are to make real headway in the social sciences. All

\footnotetext{
${ }^{11}$ For example, in economics see Axtell (2006) 2014; Beed and Kane 1991; Debreu 1991; Epstein 2005; Farmer and Foley 2009; Krugman 2009; Lo and Mueller 2010.

${ }^{12}$ See, for instance, Alexander et al. 1987; Archer 2003; Hoover 2009; Ross 2008.

${ }^{13}$ Mills 1959 and Geertz 1973 are influential critiques of "grand theorizing" in sociology and anthropology. Recent work on randomized trials in economics can be found in Banerjee et al. (2010) 2013; Duflo 2006.
} 
the data and technology in the world only gets us so far if the models that make use of it are flawed. And so it makes sense that legions of theorists, and millions in research dollars, are dedicated to exploring these models and reactions.

In recent years, however, I have begun to worry that much of this effort is misdirected. It is not that the diagnoses are wrong, but that they overlook a deeper problem. The five categories of diagnosis above are not unique to the social sciences. They are diagnoses that one might apply to meteorology, or to cell biology, or to ecology. We might be modeling meteorological phenomena at the wrong level. We might have poor models of the parts of cells. We might misunderstand how ant colonies aggregate out of interacting individual ants.

Implicit in these five diagnoses - and in the practice of the social sciences from its earliest days - is a particular analogy between the social sciences and the natural sciences. Namely, that the objects of the social sciences are built out of individual people much as an ant colony is built out of ants, or a chimpanzee community is built out of chimpanzees, or a cell is built out of organelles.

When we look more closely at the social world, however, this analogy falls apart. We often think of social facts as depending on people, as being created by people, as the actions of people. We think of them as products of the mental processes, intentions, beliefs, habits, and practices of individual people. But none of this is quite right. Research programs in the social sciences are built on a shaky understanding of the most fundamental question of all: What are the social sciences about? Or, more specifically: What are social facts, social objects, and social phenomena-these things that the social sciences aim to model and explain?

My aim in this book is to take a first step in challenging what has come to be the settled view on these questions. That is, to demonstrate that philosophers and social scientists have an overly anthropocentric picture of the social world. How the social world is built is not a mystery, not magical or inscrutable or beyond us. But it turns out to be not nearly as people-centered as is widely assumed.

The term 'anthropocentric' comes, of course, from astronomy. For centuries, astronomers believed that the features of the universe depended in a crucial way on us-on earth and on man. This illusion was natural. Anthropocentric astronomers had perfectly good reasons for believing that the sun, planets, and stars revolved around the earth. Although they ran into problems of prediction and explanation - much like the social scientists of today-they found ingenious ways of patching their theories, for example, the famous Ptolemeic "epicycles." But no refinement of their knowledge of the planets, or the mathematics of orbits, would fix the problems. What was needed was a deeper theoretical revision: they needed to abandon the anthropocentric picture of the universe. 
This is a surprising criticism to levy at social science. It is one thing to accuse medieval cosmologists of overestimating the importance of humans in the universe, but quite another to accuse the social sciences of doing so. The phenomena of the social sciences-economic systems, family relationships, education, crime, language - these are things that involve people. How could the social sciences be too anthropocentric?

People are not, of course, irrelevant to the social sciences. Social phenomena involve people. The question is how. How exactly are people involved in social facts, objects, and events? How are these things made? What roles do thoughts, actions, and practices play, and how might they fall short?

These are questions about metaphysics. They are questions about the nature of the social world. To make headway on them, we have a number of resources at our fingertips. Metaphysics has, in recent years, become one of the most careful and sophisticated disciplines in philosophy. It has developed and refined number of tools for thinking about just these kinds of questions. How does one entity depend on another entity? What are facts, and how are they grounded by other facts? And so on. Yet few of these tools have been applied in a serious way to the social world.

To be sure, many people in many traditions have theorized about the nature of the social world. From Hobbes to Hume, Comte to Mill, Herder to Durkheim, and Marx to von Mises, theories of the social world abound. The topic is also increasingly prominent in the contemporary philosophical literature. The most influential of these contemporary accounts is John Searle's. In his 1995 book The Construction of Social Reality, Searle attempts to give a reasonably comprehensive theory. ${ }^{14}$ Others have plunged in as well. Raimo Tuomela has followed up on Searle in several books, detailing more elaborate theories along similar lines. ${ }^{15}$ A different approach is taken by Margaret Gilbert in her 1989 book On Social Facts. In that book and in a series of subsequent papers, she develops nuanced theories of groups, along with the commitments, norms, and attitudes that accompany group membership. Michael Bratman focuses in particular on the actions and intentions of groups, in his influential account of shared intention. ${ }^{16}$ Philip Pettit, in his 1993 book The Common Mind, gives a theory of the nature of the social world. And in the 2011 book Group Agency, Pettit and his coauthor Christian List give a theory of the nature and actions of groups. ${ }^{17}$ Others have also developed theories of institutions, artifacts, and other man-made entities. ${ }^{18}$

\footnotetext{
${ }^{14}$ Searle 1995. He updates the view in Searle 2010.

${ }^{15}$ E.g., Tuomela 2002, 2007.

${ }^{16}$ Bratman 1993.

${ }^{17}$ List and Pettit 2011; Pettit 1993.

${ }^{18}$ E.g., Sally Haslanger, Ruth Millikan, Richard Boyd, Lynne Baker, Amie Thomasson, Crawford Elder, Frank Hindriks, Francesco Guala, Ron Mallon, and others.
} 
It is not, in other words, that social metaphysics - that is, the nature of the social world-has escaped attention. Yet only recently have people really started to examine the metaphysics in detail. Historically, questions about the nature of the social world were treated in a fairly cursory way, dispatched quickly to make way for points about morality or politics or game theory. And so the sophisticated toolkit of metaphysics mostly sat idly by. Because of this neglect, the settled view of the social world has gone more or less unchallenged.

\section{Social Metaphysics and Social Groups}

If it is true that we misunderstand the building blocks of the social world, it is no surprise that we are having trouble in the social sciences, since that misunderstanding distorts our models. Some of the most obvious cases are financial markets. Despite their prominence in the daily newspaper, just what financial markets and financial instruments are, or what their function is, has never been clear to economists. And so they have largely been left out of models, particularly models in macroeconomics. Economists have rationalizations for this: at least until 2008, it was common to argue that the "financial economy" does not bear too much on the "real economy" of houses, cars, and dish soap. ${ }^{19}$ In recent years, that argument has fallen flat, and economists have been scrambling to figure out how financial markets and instruments should figure into macroeconomic models. But that scramble does not change the basic problem. Knowing that we need to incorporate financial markets and instruments into our models does not help much if we are clueless about their building blocks. Until we improve our understanding of their nature, we do not have a prayer of modeling them well.

While the exclusion of financial markets from macroeconomics is a glaring example, it is far from the only case of a distorted understanding of the social world. In fact, the field of social metaphysics is only in its infancy. Our flawed understanding starts with much simpler things than the financial economy. Even the very simplest cases are thornier than one might imagine.

A prime example of a simple case is a group of people. The social world is rich with groups: classes, populaces, mobs, legislatures, courts, faculties, student bodies, and so on. In any social science, we are interested in investigating facts about groups, facts like the educational attainments of kindergarteners, the voting patterns of legislators, the levels of corruption in bureaucracy, the responsibilities of soldiers for the conduct of war, or the salaries of university

${ }^{19}$ See, for instance, Kydland and Prescott 1982; Lucas 1972, 1977. 
faculties. And, it seems, the building blocks of groups couldn't be any simpler. A group of people is constituted by people, no more, no less.

But this apparent simplicity is deceptive. A close look at the metaphysics of social groups shows it to be subtler than this. One trick is in the word "constituted." As I will discuss later on, it is technically true that groups of people are constituted by people. Constitution, however, has received an enormous amount of attention in the recent metaphysics literature. In the last few years, it has become clear that to say " $x$ is constituted by such-and-such" only gives a tiny bit of information about what $x$ is. It is not hard to see this. One of the examples I will be discussing in some detail is the United States Supreme Court. It is small — nine members - and very familiar, so there are lots of facts about it we can easily consider. Even a moment's reflection is enough to see that a great many facts about the Supreme Court depend on much more than those nine people. The powers of the Supreme Court are not determined by the nine justices, nor do the nine justices even determine who the members of the Supreme Court are. Even more basic, the very existence of the Supreme Court is not determined by those nine people. In all, knowing all kinds of things about the people that constitute the Supreme Court gives us very little information about what that group is, or about even the most basic facts about that group.

These quick observations about the Supreme Court raise more questions than they answer. But that, for now, is the point. Even to understand the nature of simple social groups, we need to take the metaphysics seriously. This book is written with the conviction that we are wasting our time with the most complex cases, if we get even the simple ones wrong.

Part One of this book sets out a general framework for social metaphysics. How do we approach the problems of social metaphysics, what are the projects involved, what are the tools we need, and why have people gotten it so wrong? Part Two applies the tools of social metaphysics to groups. Groups are not even close to being the only social entity. But they are important in their own right, and figuring out how to work with them gives us a template for approaching more complicated things. Groups are also a powerful example for advancing the central point of the book. My aim is to allow us to start freeing ourselves from "the ant trap" - the anthropocentric picture of the social world as being composed by individual people. For this aim, inquiry into groups strikes the target directly. If anything in the social world should be anthropocentric, it is groups of people. Even the most lukewarm defender of anthropocentrism may find it hard to see what could possibly be wrong with an anthropocentric picture of groups. Thus when, in Part Two, we see that anthropocentrism is wrong even for groups, we plant the stake deep into its heart. 